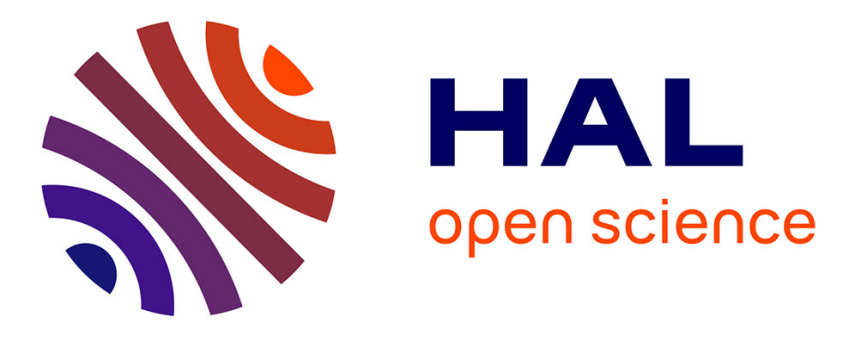

\title{
Adrenal adaptation in potassium-depleted men: role of progesterone?
}

Anne Blanchard, Sylvie Brailly Tabard, Antonin Lamaziere, Damien Bergerot, Valentina Zhygalina, Aurelien Lorthioir, Antoine Jacques, Delphine Hourton, Michel Azizi, Gilles Crambert

\section{To cite this version:}

Anne Blanchard, Sylvie Brailly Tabard, Antonin Lamaziere, Damien Bergerot, Valentina Zhygalina, et al.. Adrenal adaptation in potassium-depleted men: role of progesterone?. Nephrology Dialysis Transplantation, 2019, pii: gfz135. 10.1093/ndt/gfz135 . hal-02267731

\section{HAL Id: hal-02267731 \\ https://hal.science/hal-02267731}

Submitted on 24 Oct 2019

HAL is a multi-disciplinary open access archive for the deposit and dissemination of scientific research documents, whether they are published or not. The documents may come from teaching and research institutions in France or abroad, or from public or private research centers.
L'archive ouverte pluridisciplinaire HAL, est destinée au dépôt et à la diffusion de documents scientifiques de niveau recherche, publiés ou non, émanant des établissements d'enseignement et de recherche français ou étrangers, des laboratoires publics ou privés. 
${ }^{1,2,3}$ Blanchard $A,{ }^{4,5,6}$ Brailly Tabard $S,{ }^{7,8}$ Lamaziere A, ${ }^{3}$ Bergerot D, ${ }^{1,}{ }^{2}$. 3 Zhygalina V, ${ }^{1,2,3}$ Lorthioir A, ${ }^{9}$ Jacques A, ${ }^{9}$ Hourton D; ${ }^{1,2,3}$ Azizi M, ${ }^{10,11}$ Crambert G.

${ }^{1}$ Université Paris Descartes, Sorbonne Paris Cité, Paris, France; ${ }^{2}$ Assistance Publique Hôpitaux de Paris, Hôpital Européen Georges Pompidou, Centre d'Investigation Clinique, Paris, France; ${ }^{3}$ INSERM, ClC-1418, Paris, France; ${ }^{4}$ Faculté de Médecine Paris-Sud, Université Paris-Saclay; ${ }^{5}$ Assistance Publique Hôpitaux de Paris, Hôpital de Bicêtre, Service de Génétique Moléculaire, Pharmacogénétique et Hormonologie, F-94275 Le Kremlin Bicêtre; ${ }^{6}$ Inserm 1185 Faculté de Médecine Paris- Sud, Paris-Saclay, Le Kremlin-Bicêtre, F-94276, France; ${ }^{7}$ Assistance PubliqueHôpitaux de Paris, Hôpital Saint-Antoine, Plateforme de Métabolomique, Peptidomique et de Dosage de Médicaments; ${ }^{8}$ INSERM ERL1157, F-94276 Le Kremlin Bicêtre ; ${ }^{9}$ Assistance Publique Hôpitaux de Paris, Hôpital Européen Georges Pompidou, Unité de recherche clinique, Paris, France ; ${ }^{10}$ Sorbonne Université, INSERM, Université Paris Descartes, Sorbonne Paris Cité, UMR_S 1138, Centre de Recherche des Cordeliers, F-75006, Paris, France; ${ }^{11}$ CNRS ERL 8228 - Centre de Recherche des Cordeliers - Laboratoire de Physiologie Rénale et tubulopathies, F-75006, Paris, France.

SHORT TITLE: adrenal adaptation to potassium depletion

KEY WORDS: Potassium depletion, hypokalemia, progesterone, adrenal steroids, Gitelman syndrome

\section{CORRESPONDING AUTHOR:}

\section{Anne BLANCHARD}

Centre d'investigation Clinique, Hôpital Européen Georges Pompidou, 20-40 rue Leblanc 75015 PARIS

anne.blanchard@aphp.fr

Phone 0033156092913

Fax 0033156092929

Word count (including references)

SOURCES OF FUNDING The DRIVING trial was supported by research grants from the French Ministry of Health (CRC 2012 grant \# CRC12122).

DISCLOSURES/CONFLICT OF INTEREST The authors have no disclosures, no conflict of interest in relation to this study.

The results presented here have not been published previously in whole or part, except in abstract format.

Number of tables: 3

Number of figures: 2

Number

of supplementary

digital

content

files: 


\section{ABSTRACT}

Background: In rodents the stimulation of adrenal progesterone is necessary for renal adaptation under potassium depletion. Here we sought to determine the role of progesterone in adrenal adaptation in potassium-depleted healthy human volunteers and compared our findings to data collected in patients with Gitelman syndrome, a salt-losing

47 tubulopathy.

Methods: Twelve healthy young men were given a potassium-depleted diet for 7 days at a tertiary referral medical center (NCT02297048). We measured by LC-MS/MS plasma steroid concentrations at days 0 and 7 before and $30 \mathrm{~min}$ after treatment with tetracosactide. We compared these data to data collected in 10 Gitelman syndrome patients submitted to tetracosactide test.

Results: The potassium-depleted diet decreased plasma potassium in healthy subjects by $0.3 \pm 0.1 \mathrm{mmol} / \mathrm{l}$, decreased plasma aldosterone concentration by $50 \%(p=0.0332)$ and increased plasma 17-hydroxypregnenolone concentration by $45 \% \quad(p=0.0232)$ without affecting other steroids. CYP17 activity, as assessed by 17- hydroxypregnenolone /pregnenolone ratio increased by $60 \%(p=0.0389)$. As compared to healthy subjects,

Conclusion: The increase in 17-hydroxypregnenolone concentration after mild potassium depletion in otherwise healthy human subjects suggests that 17 hydroxylation of pregnenolone prevents the increase in progesterone observed in potassium-depleted mice. 


\section{INTRODUCTION}

Potassium is the most abundant cation in organisms, and the equilibrium between its low extracellular and high intracellular concentrations influences cellular processes and properties such as membrane resting potential and cell volume. The inability to maintain this equilibrium, and particularly to restrain extracellular plasma potassium concentration in a tight physiological range, is potentially life-threatening. The potassium balance is coordinated by mechanisms for potassium storage into and release from internal stores (internal balance) and mechanisms that regulate retention and excretion (external balance) [1]. In this complex regulatory system, the kidney, mainly the distal part of the nephron, plays an important role. In steady-state conditions, renal excretion of potassium is similar to which require a favorable electrical gradient generated by the activity of the amiloridesensitive $\mathrm{Na}^{+}$channel $\mathrm{ENaC}[2,3]$. Potassium reabsorption is mediated by the $\mathrm{H}, \mathrm{K}-\mathrm{ATPases}$, mainly the isoform HKA2 [4]. Excretion and reabsorption are functional under physiological conditions [5]. In subjects on a low-potassium diet condition, the renal switch from a high rate of potassium secretion to efficient potassium conservation is mediated by a number of complementary mechanisms: 1) an increase in electroneutral (mediated by the $\mathrm{Na}-\mathrm{Cl}$ cotransporter NCC) versus electrogenic (mediated by ENaC) $\mathrm{Na}^{+}$reabsorption [6]; 2) a decrease in plasma aldosterone concentration, which induces a decreased activity of ENaC [7]; 3) inhibition of ROMK through a pathway dependent on reactive-oxygen species [8]; 4) the progesterone-dependent stimulation of the $\operatorname{HKA2}[4,9]$; and 5) the proliferation of tubular epithelial cells of the distal nephron, which occurs in chronic conditions [10].

In rodents in a potassium-depleted state, there is stimulation of adrenal secretion of progesterone and progesterone-dependent stimulation of HKA2 expression suggesting that progesterone is not just a sex hormone $[9,11]$. This offers a new promising way in treating or preventing renal hypokalemia by stimulating potassium reabsorption rather than inhibiting its secretion. This potassium-sparing effect of adrenal progesterone has only been described in rodent while the stimulation of adrenal Progesterone synthesis by $\mathrm{K}$ depletion may not be effective in human. Indeed, the presence in human adrenal gland of the cytochrome p450 family member CYP17A1, an enzyme that is not expressed in rodent [12], 
102 metabolizes progesterone into 17-hydroxyprogesterone and may prevent progesterone 103 accumulation [13] (Figure 1).

104

105 To address the role of progesterone in renal adaptation to potassium depletion in humans, 106 we submitted healthy subjects to a potassium-depleted diet and studied their renal 107 adaptation to potassium depletion, the changes induced in plasma adrenal steroid 108 concentrations, and their responses to adrenocorticotropic hormone (ACTH) stimulation 109 following tetracosactide (Synacthene ${ }^{\circledR}$ ) administration. Finally, plasma adrenal steroids were 110 quantified in patients with chronic severe renal hypokalemia related to a congenital salt111 losing tubulopathy, the Gitelman syndrome. 


\section{SUBJECTS AND METHODS}

\section{SUBJECTS}

The study was approved by the local Ethics Committee (P120906 - CPP Ile de France VI, NCT02297048). All subjects gave informed consent for genetic analyses before participating

\section{INVESTIGATIONS}

After a safety inclusion visit, healthy subjects were subjected twice to a 7-day period of potassium depletion. Potassium depletion was induced by $30 \mathrm{~g}$ daily sodium polystyrene sulfonates (Kayexalate ${ }^{\circledR}$, Sanofi-adventis France) over two days, followed by 5 days under a low-potassium diet $(25 \mathrm{mmol} / \mathrm{d})$. We attempted to maintain a constant level of calories and of sodium intake during the diet period. A safety end-study visit was performed a 7-day washout period after the second potassium-depletion interval.

The day before admission for each experimental visit, participants were asked to collect urine for measurement of 24-h urinary output and determination of urinary concentration of electrolytes ( $\mathrm{Na}, \mathrm{K}, \mathrm{Cl}$, and creatinine) and of steroid metabolites. At the beginning (day 1 , D1) or the end of potassium depletion (day 7, D7), blood samples were taken before drug administration at about 9:00 a.m. after an overnight fast and after $1 \mathrm{~h}$ of rest in the sitting position (time HO). Additional blood samples were taken $30 \mathrm{~min}$ after intravenous 
administration of $250 \mu \mathrm{g}$ tetracosactide (time H1; Synacthene ${ }^{\circledR}$, alfasigma). Samples at H0 allowed determination of plasma electrolytes including sodium, potassium, chloride, bicarbonate, creatinine, and plasma renin concentration, plasma aldosterone, plasma ACTH, and of steroids. At H1, plasma renin and plasma aldosterone were quantified. The patients with Gitelman syndrome were given the tetracosactide test once; the same parameters that were measured in the healthy volunteers were measured in the Gitelman syndrome patients.

\section{METHODS}

Plasma concentrations of a panel of 15 steroids were measured using a liquid chromatography coupled to tandem mass spectroscopy (LC-MS/MS) assay to avoid the risk of interference between steroids as previously described [14]. The steroids evaluated were pregnenolone, progesterone, corticosterone, deoxycorticosterone (DOC), aldosterone, 17hydroxypregnenolone, 17-hydroxyprogesterone, 11-deoxycortisol, 21-deoxycortisol, cortisol, cortisone, DHEA, delta 4-androstenedione, 11- $\beta$-hydroxyandrostenedione, testosterone.

Plasma renin concentration was assessed with commercial kit (Renin III from CisBio). Urinary concentrations of cortisol and plasma concentrations of ACTH were determined using chemiluminescent enzyme immunoassays (Immulite 2000 XPi, Siemens Healthineers).

Routine plasma and urinary aldosterone concentrations were also assessed with a commercial kit (DPC Coat-a-Count assay from Diagnostic Products Corp).

\section{STATISTICAL ANALYSIS}

Our hypothesis was that potassium depletion would increase adrenal progesterone and/or 17-hydroxyprogesterone synthesis. The primary outcome was the change induced by potassium depletion in the plasma progesterone concentration measured $30 \mathrm{~min}$ after intravenous administration of $250 \mu \mathrm{g}$ tetracosactide. This was a pilot study without preliminary data in humans, therefore, there was no data that could be used to support the calculation of necessary sample size for statistical significance. In male mice subjected to potassium depletion, there was a stimulation of progesterone production by $300 \%$ [9]. Assuming only a $50 \%$ increase in progesterone after potassium depletion (mean difference +0.03 [IC95\% : +0.02; -0.08]; $\mathrm{p}$ < 0.2827), an estimated standard deviation (SD) of $0.05 \mathrm{pg} / \mathrm{ml}$, 
and a two-sided type 1 error rate of $0.05 \%$, a sample size of 12 evaluable subjects would yield $80 \%$ power.

Analysis of variance for normally distributed variables or the Kruskal-Wallis non-parametric test for non-normally distributed variables were used to compare the characteristics between genotypes. In most cases, data were log-transformed when they were not normally distributed. To compare values from $\mathrm{DO}$ to $\mathrm{D} 7$ or from $\mathrm{HO}$ to $\mathrm{H} 1$, paired t tests were performed, whereas independent sample t tests were used to compare values of Gitelman patients with values of healthy subjects. All analyses were carried out using SAS Statistical Software (version 9.4, SAS Institute), and $p<0.05$ was considered to be significant. Results are expressed as median [IQR: Q1;Q3].

\section{RESULTS}

\section{EFFECT OF POTASSIUM DEPLETION IN HEALTHY SUBJECTS}

As expected, when values were compared for healthy subjects on D0 versus D7, plasma potassium concentration decreased (mean difference $0.3 \pm 0.1 \mathrm{mmol} / \mathrm{l}, \mathrm{p}=0.0180$, Table 1 ), and subjects became slightly hypokalemic without change in plasma concentrations of sodium, chloride, bicarbonate, creatinine, or estimated glomerular filtration rate (Table 1). Potassium depletion induced a decrease (by a factor of 2 ) in daily urinary excretion of potassium (Table 1) without affecting daily urinary excretion or fractional excretion of sodium (Table 1 ).

As measured by immunoassay, plasma aldosterone concentration and urinary aldosterone excretion decreased by $-55 \%$ ([IC95: -72\%;-28\%]; $p=0.0068)$ and -69\% ([IC95: -80\%; -51\%]; $p=0.0001$ ), respectively, from D0 to D7 in healthy subjects (Table 1). This is likely due to the inhibitory effect of potassium depletion on aldosterone secretion since the plasma renin concentration was not significantly affected (Table 1). Plasma ACTH and urinary cortisol excretion ( $\mathrm{nmol} / \mathrm{mmol}$ creatinine) (Table 1 ) and plasma cortisol (Table 2) were not affected by potassium depletion. 
A week of potassium depletion did not affect any of the plasma steroid concentrations as assessed by LC-MS/MS (Table 2, healthy subjects, DO vs. D7) with the exceptions of aldosterone, which decreased by $-50 \% \quad$ ([IC95\% $-80 \% ;-10 \%] ; \quad p=0.0332)$ and $17-$ hydroxypregnenolone, which increased by $45 \%$ [IC95\% 9\%; +67\%]; $p=0.0232$ ). Of note, concentrations of plasma progesterone (mean difference 20\% [IC95 \% -24\%; +49\%], $\mathrm{p}=0.283$ ) and its metabolite 17-hydroxyprogesterone (mean difference $+11 \%$ [IC95 \% $-9 \%$; $+28 \%$ ], p 0.237) were similar before and after a week of potassium, depletion (Table 2).

We then estimated enzymatic activity of adrenal steroidogenesis by calculating the ratio between the product and substrate of enzymes (Figure 1, Supplemental Table 1). This analysis identified two changes in important steps of the steroidogenesis in healthy subjects after potassium depletion. First, the activity of CYP11B2, estimated as the ratio of aldosterone to corticosterone was 3-4-fold decreased. Second, less expectedly, CYP17 activity, estimated as the ratio of 17-hydroxypregnolone to pregnolone, was increased by $60 \%$. The stimulation of CYP17 was associated with no change in estimated activity of 3- $\beta$ hydroxysteroid dehydrogenase (3ßOHSD) in the glomerulosa and a decrease in estimated $3 \beta$ OHSD activity in the fasciculata, which prevented conversion of 17-hydroxypregnolone into 17-hydroxyprogesterone.

Intravenous administration of $250 \mu \mathrm{g}$ tetracosactide led to a 2-fold increase in plasma cortisol, a 4-fold increase in plasma aldosterone, and a significant increase in all plasma hormonal concentrations except renin, testosterone, and cortisone (Table 2). Post tetracosactide concentrations of steroids measured under usual diet (D0) and after a week under low potassium diet (D7) were similar.

\section{EFFECT OF CHRONIC POTASSIUM DEPLETION}

The effect of a severe and chronic depletion of potassium was addressed in patients suffering of a salt and potassium loosing nephropathy, the Gitelman syndrome (GS) (OMIM \#263800). As shown in Table 1, patients with GS were older than healthy subjects ( $p<$ 0.0001 ) but had similar BMI ( $p=0.1765)$, and their diastolic blood pressure was slightly higher than that of healthy subjects (Table 1). Patients with the salt-losing tubulopathy had marked activation of the renin angiotensin-aldosterone system and high sodium intake (as 
demonstrated by higher levels of sodium excretion) as compared to controls (Tables 1 and 3). They had marked hypokalemia, abnormal levels of potassium excretion (i.e., K excretion > $40 \mathrm{mmol} / 24 \mathrm{~h}$ and fractional excretion of $\mathrm{K}$ higher than 5\%). Their plasma ACTH was similar to that of healthy subjects (Table 1 ).

Despite their chronic hypokalemia, GS patients did not display any differences in pretetracosactide plasma steroid concentrations compared to healthy subjects with the exceptions of lower levels of aldosterone (mean difference $69 \%$ [IC95 \% +33\%; +86\%], p 0.0046) and of higher levels of 11-deoxycortisol and of delta 4-androstenedione (mean differences $+44 \%[$ [C95\% +1\%; +68\%], $p=0.0471$ and 19\% [IC95 \% +0\%; +34\%], p=0.0485, respectively) (Table 2 ).

GS patients had a stronger response to tetracosactide than healthy subjects (Table 3). As expected, in GS patients post-tetracosactide plasma aldosterone concentration was markedly higher than in healthy subjects $(+67 \%[+44 \% ;+80 \%], p=0.0003)$. In addition, the post-tetracosactide concentrations of pregnenolone, progesterone, corticosterone, DOC, and 11-deoxycortisol were about $40 \%$ higher in GS patients than in healthy subjects, whereas cortisol and delta 4 -androstenedione levels were $20-30 \%$ higher. This exacerbated response to tetracosactide could be, depending of the steroid, related either to the observed chronic stimulation of angiotensin II or to chronic potassium depletion. To distinguish between these possibilities, we calculated the correlation between posttetracosactide plasma steroid levels and plasma renin (which are high when angiotensin II activity is high) or plasma potassium values. We found that progesterone, corticosterone, DOC, and aldosterone were correlated with both plasma renin and plasma potassium levels (Supplemental Table 2, Figure 2 A-D), whereas pregnenolone and delta 4-androstenedione only correlated with plasma potassium concentration (Figure $2 \mathrm{E}-\mathrm{H}$ ). Interestingly, aldosterone (Figure $2 \mathrm{~A}-\mathrm{B}$ ) and DOC (Supplemental Table 2) best fitted with plasma renin concentration, whereas progesterone best fitted with plasma potassium level (Figure 2 C-D).

\section{DISCUSSION}

MILD REDUCTION OF POTASSIUM INTAKE DOES NOT INFLUENCE PROGESTERONE AND 17HYDROXYPROGESTERONE CONCENTRATIONS IN MEN 
Although it is clear that steroid production by the adrenal gland changes in response to sodium and potassium content of the diet $[15,16]$, almost nothing was known about adaptation of humans to a low potassium diet except that plasma aldosterone concentration falls markedly after 2-3 days of potassium depletion [17]. Elabida et al. demonstrated in mice that potassium depletion but not sodium depletion, led to increase in adrenal progesterone production [9]. Potassium depletion induced an increased expression of steroidogenic acute regulatory protein (StAR), CYP11A1, and 3BHSD1 and was associated with decreased in CYP11B1 expression (a key enzyme in corticosterone synthesis) and in CYP11B2 expression (a key enzyme for aldosterone synthesis). Using a mathematical model of steroidogenesis in mice, Elabida et al. predicted that potassium depletion should result in an increase in plasma progesterone, a prediction confirmed experimentally in male mice and male men [9]. In mice progesterone regulates renal potassium handling both in males and females under potassium restriction, independently of its role in reproduction, and this adrenal progesterone was required for full adaptation to potassium depletion [9]. The mechanism was mediated by stimulation of the H,K-ATPase type 2 and was prevented by the progesterone receptor antagonist RU486. These results, however, were not immediately transferable to man since human adrenal steroidogenesis strongly differs from that of rodents as humans express CYP17, which metabolizes progesterone into 17hydroxyprogesterone, although Elabida et al. also established a weak correlation between plasma progesterone in men and their potassium intake [9].

To directly address the contribution of progesterone on renal adaptation to potassium depletion in human, we induced potassium depletion in healthy men. Although we did not measure intracellular potassium levels, the marked inhibition of plasma and urinary aldosterone concentrations were indicative of a state of potassium depletion. At the beginning and the end of the period, we performed a tetracosactide test to stress the adrenal response to potassium depletion and potentially reveal subtle modifications in adrenal steroidogenesis. Neither progesterone nor 17-hydroxyprogesterone concentrations measured before or after tetracosactide administration were affected by potassium restriction. However the potassium depletion we induced may have been too weak (decrease by 2 -fold of potassium intake) or too short (7 days) or both as compared to what has been done in mice (decrease by 20 -fold of potassium intake for 1 week). In male mice, 
the increase of progesterone appears to stimulate potassium reabsorption to counteract the deleterious effect of prolonged potassium restriction. This step was not observed in healthy subjects in our present study. In addition, the presence of a CYP17A activity in human adrenal glands may have prevented progesterone accumulation. In support of this, we observed a significant 50\% increase in 17-hydroxypregnenolone and, unexpectedly, the estimated CYP17 activity increased by $60 \%$. Our results suggest that this increase in CYP17 activity leads to 17-hydroxypregnenolone accumulation but that conversions of pregnenolone into progesterone and 17-hydroxypregnenolone into 17-hydroxyprogesterone are prevented by low $3 \beta$ OHSD activity (Figure 1). Our study was powered to demonstrate a $50 \%$ increase in plasma progesterone and 17-hydroxyprogesterone concentrations, whereas 150 subjects would be required to demonstrate that the observed $20 \%$ increase in pretetracosactide progesterone concentration was significant.

\section{PATIENTS WITH SALT-LOSING TUBULOPATHIES HAD ALTERED ADRENAL RESPONSE TO TETRACOSACTIDE BUT UNAFFECTED PROGESTERONE METABOLISM}

We also studied the plasma steroid profile in patients with a congenital renal loss of sodium and potassium due to a Gitelman syndrome. These patients had a severe chronic hypokalemia (median $2.7 \mathrm{mmol} / \mathrm{l}$, Table 1 ), a renal loss of sodium, resulting in marked stimulation in plasma renin and aldosterone concentrations, and high potassium intake. In contrast to observations in rodents, despite profound hypokalemia, GS patients displayed a hyperaldosteronism in response to their loss of salt and are under potassium supplementation to limit their hypokalemia. The levels of plasma progesterone and 17hydroxyprogesterone were similar to those observed in healthy subjects. Interestingly, after treatment with tetracosactide, levels of many steroids were more elevated in GS patients than in healthy subjects. These results indicate that patients with GS have a higher ability than healthy subjects to respond to ACTH stimulation in order to promote steroid production. Since, these patients displayed stimulation of their renin-angiotensinaldosterone system (Tables 2 and 3), we suggest that the presence of high levels of angiotensin II sensitizes the adrenal glands of GS patients to ACTH. This synergic effect of angiotensin II and ACTH on steroid production was originally documented about 35 years ago [18]. Indeed, angiotensin II not only increases the expression of CYP11B2, but also indirectly stimulates the activities of 3ßHSD2 and CYP21 enzymes [19]. GS patients are, 
333 however, in a paradoxical situation since they exhibit a profound hypokalemia that probably 334 counteracts, at least partially, the effect of angiotensin II. When ACTH is given to GS 335 patients, it disrupts this fragile equilibrium and reveals a "hidden" hyperactivity of the 336 adrenal glands, which produce steroids like progesterone with a good correlation to plasma 337 potassium level.

338 In conclusion, we provide evidence that potassium depletion induced in healthy men 339 enhances CYP17 adrenal activity, blunting progesterone accumulation. It is important to 340 note that our data do not exclude the possibility that an adrenal steroid-dependent pathway 341 is involved in adaptation to more severe potassium depletion. We unexpectedly observed 342 over-response to tetracosactide of non-mineralocorticoid steroids in GS patients suggesting 343 that adrenal glands not only adapt to sodium depletion but also to potassium depletion

\section{Acknowledgments}

346 This work was supported by the "Contrat de Recherche Clinique from the Assistance 347 Publique des Hôpitaux de Paris" (grant \#: CRC 12122). We thank the healthy volunteers and 348 the patients who participated in the study. We thank Dr Valerie Paquet for the recruitment 349 of healthy volunteers, the nursing staff of the Clinical Investigation Center who ran the 350 protocol, especially head nurse Jeanne Meunier. 


\section{REFERENCES}

353 1. Gumz ML, Rabinowitz L, Wingo CS. An Integrated View of Potassium Homeostasis. N Engl J Med 2015;373(1):60-72 1998;274(5 Pt 2):F817-833
3. Wang WH, Giebisch $\mathrm{G}$. Regulation of potassium (K) handling in the renal collecting duct. Pflugers Arch 2009;458(1):157-168

4. Crambert G. H-K-ATPase type 2: relevance for renal physiology and beyond. Am J Physiol Renal Physiol 2014;306(7):F693-700

5. Salhi A, Centeno G, Firsov D, et al. Circadian expression of H,K-ATPase type 2 contributes to the stability of plasma K(+) levels. FASEB J 2012;26(7):2859-2867
6. Todkar A, Picard N, Loffing-Cueni D, et al. Mechanisms of renal control of potassium homeostasis in complete aldosterone deficiency. J Am Soc Nephrol 2015;26(2):425-438

7. Frindt G, Houde V, Palmer LG. Conservation of $\mathrm{Na}+$ vs. $\mathrm{K}+$ by the rat cortical collecting duct. Am J Physiol Renal Physiol 2011;301(1):F14-20

8. Wang W. Regulation of renal K transport by dietary K intake. Annu Rev Physiol 2004;66:547-569

9. Elabida B, Edwards A, Salhi A, et al. Chronic potassium depletion increases adrenal progesterone production that is necessary for efficient renal retention of potassium. Kidney Int 2011;80(3):256-262

10. Cheval L, Duong Van Huyen JP, Bruneval P, et al. Plasticity of mouse renal collecting duct in response to potassium depletion. Physiol Genomics 2004;19(1):61-73

11. Wingo CS, Greenlee MM. Progesterone: not just a sex hormone anymore? Kidney Int 2011;80(3):231-233

12. Perkins LM, Payne AH. Quantification of P450scc, P450(17) alpha, and iron sulfur protein reductase in Leydig cells and adrenals of inbred strains of mice. Endocrinology $1988 ; 123(6): 2675-2682$

13. Brock BJ, Waterman MR. Biochemical differences between rat and human cytochrome P450c17 support the different steroidogenic needs of these two species. Biochemistry 1999;38(5):1598-1606

14. Fiet J, Le Bouc Y, Guechot J, et al. A Liquid Chromatography/Tandem Mass Spectometry Profile of 16 Serum Steroids, Including 21-Deoxycortisol and 21- 
384 Deoxycorticosterone, for Management of Congenital Adrenal Hyperplasia. J Endocr Soc $385 \quad 2017 ; 1(3): 186-201$

386 15. Hansen GP, Tisher CC, Robinson RR. Response of the collecting duct to disturbances 387 of acid-base and potassium balance. Kidney Int 1980;17(3):326-337

388 16. Kaplan NM, Barter FC. The effect of ACTH, renin, angiotensin II, and various 389 precursors on biosynthesis of aldosterone by adrenal slices. J Clin Invest 1962;41:715-724

390 17. Tremblay A, Waterman MR, Parker KL, et al. Regulation of rat adrenal messenger 391 RNA and protein levels for cytochrome P-450s and adrenodoxin by dietary sodium depletion 392 or potassium intake. J Biol Chem 1991;266(4):2245-2251

393 18. Parker LN, Lifrak ET, Kawahara CK, et al. Angiotensin II potentiates ACTH-stimulated 394 adrenal androgen secretion. J Steroid Biochem 1983;18(2):205-208

395 19. Nogueira EF, Xing Y, Morris CA, et al. Role of angiotensin II-induced rapid response 396 genes in the regulation of enzymes needed for aldosterone synthesis. J Mol Endocrinol $397 \quad 2009 ; 42(4): 319-330$ 
FIGURE 1: Effect of potassium depletion on adrenal steroidogenesis. Activities of the main enzymes of adrenal steroidogenesis were estimated by calculation of the product to

FIGURE 2: Correlation of post-tetracosactide concentrations of plasma hormones with plasma renin or plasma potassium concentrations. The individual concentrations of plasma hormones were measured after administration of $250 \mu \mathrm{g}$ tetracosactide in healthy subjects under normal diet or in Gitelman patients and correlated to the plasma renin concentration or the plasma K level. Nonparametric Spearman coefficient r [CI95\%] and p values of the correlations were calculated using Prism 8 software.

Conflict of interests: There are no conflicts of interests and the results presented in this paper have not been published previously in whole or part. 

depletion on hemodynamic, plasma, and urinary electrolytes and hormones. ${ }^{a}$

\begin{tabular}{|c|c|c|c|c|}
\hline \multirow[b]{2}{*}{ Parameters } & & \multicolumn{2}{|c|}{ Healthy subjects ( $n=12)$} & \multirow[t]{2}{*}{ GS patients $(n=10)$} \\
\hline & & DO & D7 & \\
\hline Age & yrs & $27.4[22.6 ; 30.7]$ & - & $46.2[39.4 ; 49.5]^{c}$ \\
\hline BMI & $\mathrm{kg} / \mathrm{m}^{2}$ & $23.9[20.8 ; 25.4]$ & - & $25.2[22.5 ; 27.2]$ \\
\hline SBP & $\mathrm{mmHg}(\mathrm{HO})$ & $121[115 ; 127]$ & $118[117 ; 127]$ & $120[115 ; 122]$ \\
\hline DBP & $\mathrm{mmHg}(\mathrm{HO})$ & $65[64 ; 70]$ & $70[65 ; 74]$ & $81[74 ; 85]^{c}$ \\
\hline \multicolumn{5}{|l|}{ Plasma } \\
\hline Sodium & $\mathrm{mmol} / \mathrm{L}$ & $139[137 ; 141]$ & $140[138 ; 141]$ & $138[137 ; 139]$ \\
\hline K & $\mathrm{mmol} / \mathrm{L}$ & $3.6[3.5 ; 3.9]$ & $3.4[3.2 ; 3.7]^{\mathrm{b}}$ & $2.7[2.0 ; 3.1]^{c}$ \\
\hline $\mathrm{Cl}$ & $\mathrm{mmol} / \mathrm{L}$ & $105[103 ; 106]$ & $104[103 ; 106]$ & $97[94 ; 98]^{c}$ \\
\hline Bicarbonate & $\mathrm{mmol} / \mathrm{L}$ & $27[26 ; 28]$ & $27[27 ; 29]$ & $87[72 ; 96]$ \\
\hline eGFR (MDRD) & $\mathrm{ml} / \mathrm{min} / 1.73 \mathrm{~m}^{2}$ & $103[83 ; 112]$ & $100[90 ; 108]$ & \\
\hline ACTH & $\mathrm{pg} / \mathrm{mL}(\mathrm{HO})$ & $18[14 ; 28]$ & $19[14 ; 27]$ & $18[13 ; 28]$ \\
\hline Renin & $\mathrm{mUI} / \mathrm{L}(\mathrm{HO})$ & $14[12 ; 16]$ & $12[6 ; 17]$ & $159[96 ; 200]^{c}$ \\
\hline Aldosterone & $\mathrm{pg} / \mathrm{mL}(\mathrm{HO})$ & $67[40 ; 83]$ & $23[17 ; 34]^{a}$ & $237[67 ; 359]^{c}$ \\
\hline \multicolumn{5}{|l|}{ Urine } \\
\hline Urine output & $\mathrm{l} / 24 \mathrm{~h}$ & $1.7[0.8 ; 2.4]$ & $1.5[1.1 ; 2.0]$ & $2.2[1.7 ; 2.4]$ \\
\hline $\mathrm{Na}$ & $\mathrm{mmol} / 24 \mathrm{~h}$ & $136[80 ; 200]$ & $155[103 ; 192]$ & $231[187 ; 305]^{c}$ \\
\hline K & $\mathrm{mmol} / 24 \mathrm{~h}$ & $57[36 ; 72]$ & $25[21 ; 32]^{\mathrm{b}}$ & $117[98 ; 138]^{c}$ \\
\hline $\mathrm{Cl}$ & $\mathrm{mmol} / 24 \mathrm{~h}$ & $147[89 ; 185]$ & $163[105 ; 198]$ & $304[256 ; 383]^{c}$ \\
\hline Creatinine & $\mathrm{mmol} / 24 \mathrm{~h}$ & $14[12 ; 18]$ & $16[15 ; 18]$ & $15[13 ; 18]$ \\
\hline Na excretion & $\%$ & $0.5[0.4 ; 0.6]$ & $0.5[0.5 ; 0.6]$ & $0.9[0.7 ; 1.1]^{c}$ \\
\hline K excretion & $\%$ & $8.3[5.8 ; 10.6]$ & $3.6[2.9 ; 3.9]^{b}$ & $23.2[19.1 ; 29.1]^{c}$ \\
\hline Aldosterone/creatinine & $\mathrm{ng} / \mathrm{mmol}$ & $0.52[0.33 ; 0.63]$ & $0.19[0.07 ; 0.26]^{b}$ & $1.56[0.96 ; 3.07]^{\mathrm{c}}$ \\
\hline Cortisol/creatinine & $\mathrm{ng} / \mathrm{mmol}$ & $14[10 ; 25]$ & $16[12 ; 27]$ & $43[42 ; 44]$ \\
\hline
\end{tabular}
days of a low-potassium diet $(25 \mathrm{mmol} /$ day). Blood and urine samples were taken at baseline (D0) and day 7 (D7). Results are median [IQR] and $p$ value of geometric means. ${ }^{b} p<0.05$ D7 vs. D0 ${ }^{c} p<$ 0.05 GS vs. healthy subjects DO. Abbreviations: BMI, body mass index;SBP, systolic blood pressure;DBP, diastolic blood pressure;eGFR, estimated glomerular filtration rate;ACTH, adrenocorticotropic hormone. 


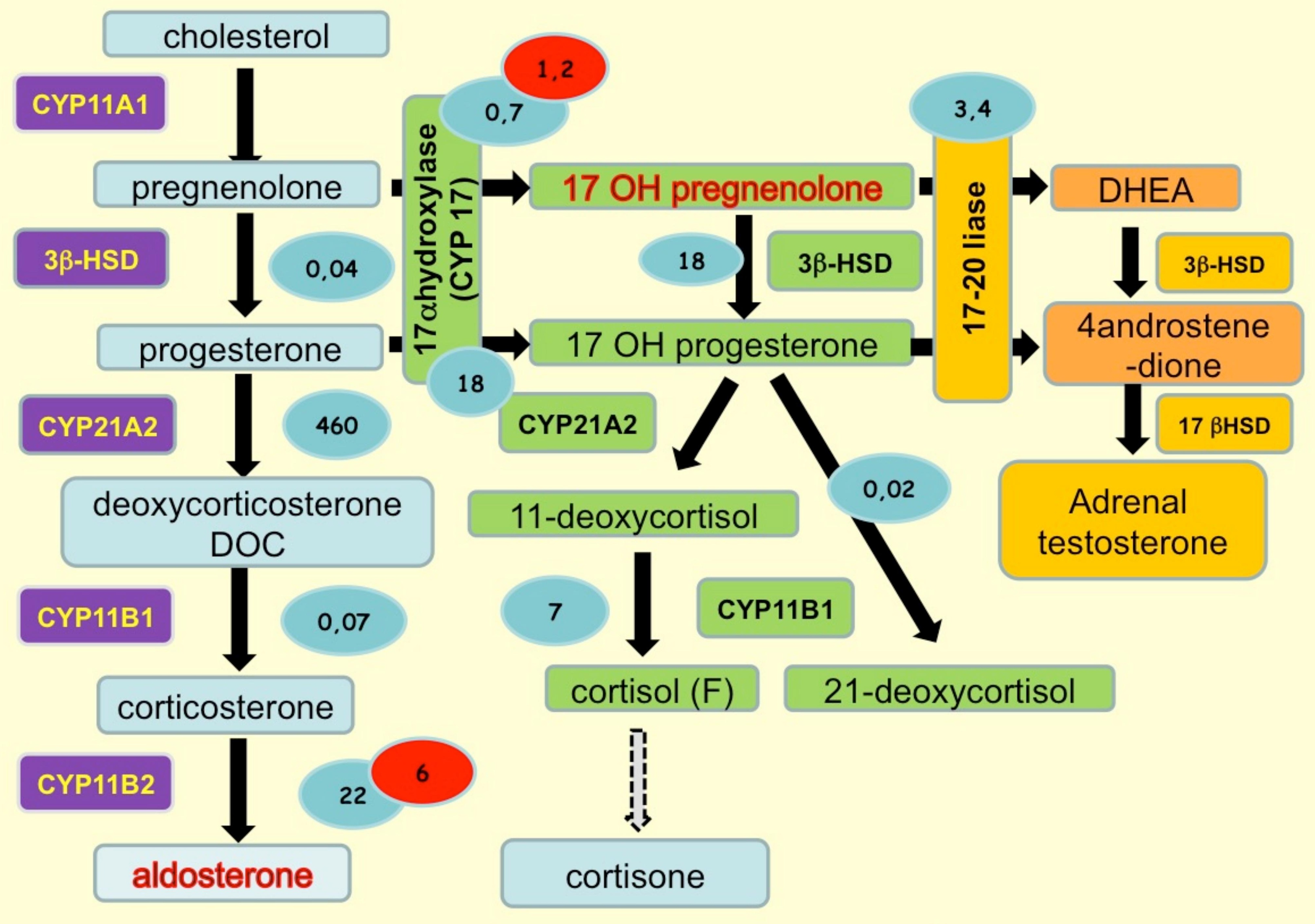



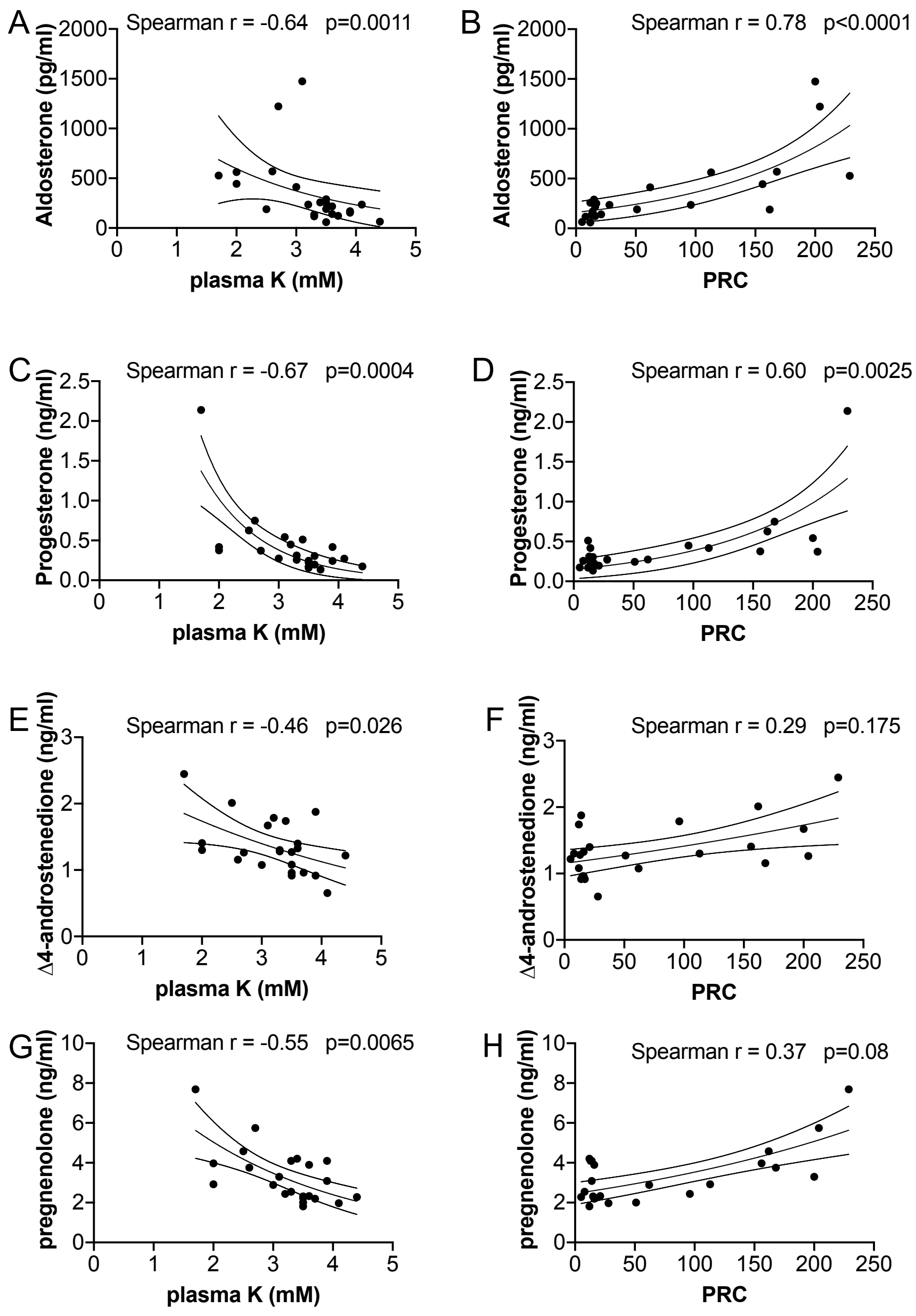